Erratum

\title{
Erratum to "The Inhibition of P-Selectin Reduced Severe Acute Lung Injury in Immunocompromised Mice"
}

\author{
Yang Liu, ${ }^{1}$ Du Xiang, ${ }^{1}$ Fang Gao, ${ }^{2}$ Hanlin Yao, ${ }^{1}$ Qifa Ye $\mathbb{D}^{1,3}$ and Yanfeng Wang ${ }^{1}{ }^{1}$ \\ ${ }^{1}$ Zhongnan Hospital of Wuhan University, Institute of Hepatobiliary Diseases of Wuhan University; Transplant Center of \\ Wuhan University, Hubei Key Laboratory of Medical Technology on Transplantation, Wuhan 430071, China \\ ${ }^{2}$ Binzhou People's Hospital Health Management Center, Binzhou 256600, Shandong Province, China \\ ${ }^{3}$ Research Center of National Health Ministry on Transplantation Medicine Engineering and Technology, \\ The 3rd Xiangya Hospital of Central South University, Changsha 410000, China
}

Correspondence should be addressed to Yanfeng Wang; yanfengwang@whu.edu.cn

Received 14 August 2021; Accepted 14 August 2021; Published 28 September 2021

Copyright (c) 2021 Yang Liu et al. This is an open access article distributed under the Creative Commons Attribution License, which permits unrestricted use, distribution, and reproduction in any medium, provided the original work is properly cited.

In the article titled "The Inhibition of P-Selectin Reduced Severe Acute Lung Injury in Immunocompromised Mice" [1], the incorrect file for Figures 6(a) and 6(g) was used during the production process and the figure should be corrected as follows: 


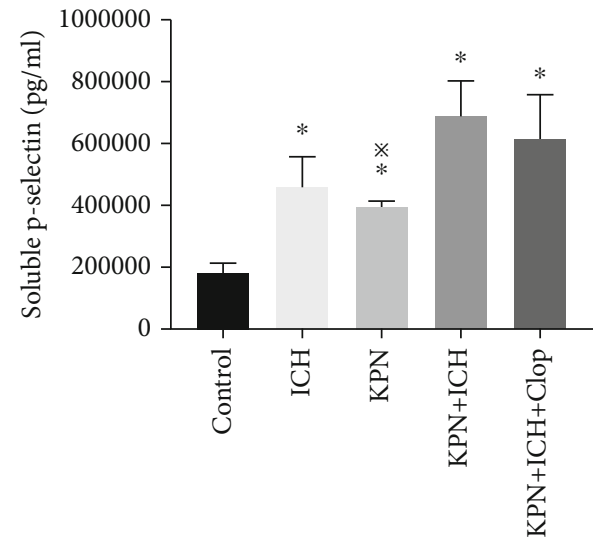

(a)

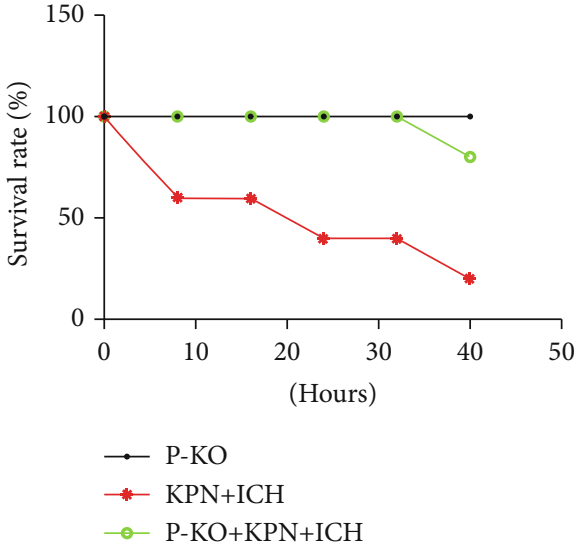

(g)

FIGURE 6: Knockout of p-selectin alleviate acute lung injury in ICH mice. (a) The expression of serum P-selectin in mice and (g) the survival curve of mice.

\section{References}

[1] Y. Liu, D. Xiang, F. Gao, H. Yao, Q. Ye, and Y. Wang, "The Inhibition of P-Selectin Reduced Severe Acute Lung Injury in Immunocompromised Mice," Oxidative Medicine and Cellular Longevity, vol. 2020, Article ID 8430465, 13 pages, 2020. 